\title{
CONTRACTIONS AND THE SPECTRAL CONTINUITY FOR $k$-QUASI-PARANORMAL OPERATORS
}

\author{
FUGEN GAO AND XiAOCHUN Li
}

\begin{abstract}
For a positive integer $k$, an operator $T \in B(\mathscr{H})$ is called $k$-quasi-paranormal if $\left\|T^{k+1} x\right\|^{2} \leqslant\left\|T^{k+2} x\right\|\left\|T^{k} x\right\|$ for all $x \in \mathscr{H}$, which is a common generalization of paranormal and quasi-paranormal. In this paper, firstly we prove that if $T$ is a contraction of $k$-quasi-paranormal operators, then either $T$ has a nontrivial invariant subspace or $T$ is a proper contraction and the nonnegative operator $D_{\lambda}=T^{* k}\left(\left|T^{2}\right|^{2}-2 \lambda|T|^{2}+\lambda^{2} I\right) T^{k}$ for $0<\lambda \leqslant 1$ is a strongly stable contraction; secondly we prove that $k$-quasi-paranormal operators are not supercyclic; at last we prove that the spectrum is continuous on the class of all $k$-quasi-paranormal operators.
\end{abstract}

Mathematics subject classification (2010): 47B20, 47A63.

Keywords and phrases: Contractions, $k$-quasi-paranormal operators, spectral continuity.

\section{REFERENCES}

[1] A. Aluthge, On p-hyponormal operators for $0<p<1$, Integral Equations and Operator Theory 13 (1990), 307-315.

[2] S. K. Berberian, Approximate proper vectors, Proc. Amer. Math. Soc. 13 (1962), 111-114.

[3] P. S. BouRdon, Orbits of hyponormal operators, Michigan Math. 44 (1997), 345-353.

[4] J. B. CONWAY AND B. B. MorRel, Operators that are points of spectral continuity, Integral Equation Operator Theory 2 (1979), 174-198.

[5] S. V. DJORDJEvić, Continuity of the essential spectrum in the class of quasihyponormal operators, Vesnik Math. 50 (1998), 71-74.

[6] S. V. DJordjević AND Y. M. Han, Browder's theorem and spectral continuity, Glasgow Math. J. 42 (2000), 479-486.

[7] B. P. DugGal, C. S. Kubrusly And N. LeVAn, Paranormal contractions and invariant subspaces, J. Korean Math. Soc. 40 (2003), 933-942.

[8] B. P. Duggal, I. H. JEON AND I. H. KIM, Continuity of the spectrum on a class of upper triangular operator matrices, J. Math. Anal. Appl. 370 (2010), 584-587.

[9] D. R. FARenick And W. Y. LeE, Hyponormality and spectra of Toeplitz operators, Trans. Amer. Math. Soc. 348 (1996), 4153-4174.

[10] T. FuRUTA, On the class of paranormal operators, Proc. Japan Acad. 43 (1967), 594-598.

[11] T. FURUTA, Invitation to Linear Operators, Taylor and Francis, London, 2001.

[12] T. Furuta, M. ITO AND T. YAMAZAKI, A subclass of paranormal operators including class of log-hyponormal and several classes, Sci. Math. 1, 3 (1998), 389-403.

[13] F. GAO AND X. LI, qit On $k$-quasi-paranormal operators, J. Math. Inequal. 8, 1 (2014), 113-122.

[14] F. GAO AND X. FANG, Generalized Weyl's theorem and spectral continuity for quasi-class $(A ; k)$ operators, Acta Sci. Math. 78 (2012), 241-250.

[15] P. R. Halmos, A Hilbert Space Problem Book, Springer-Verlag, New York, 1982.

[16] I. S. HWANG AND W. Y. LeE, On the continuity of spectra of Toeplitz operators, Arch. Math. 70 (1998), 66-73.

[17] I. S. HWANG AND W. Y. LEE, The spectrum is continuous on the set of p-hyponormal operators, Math. Z. 235 (2000), 151-157.

[18] K. B. Laursen and M. M. Neumann, Introduction to Local Spectral Theory, Clarendon Press, Oxford, 2000. 
[19] S. MECHERI, Bishop's property ( $\beta$ ) and Riesz idempotent for k-quasi-paranormal operators, Banach J. Math. Anal. 6, 1 (2012), 147-154.

[20] S. SÁNCHEZ-PERALES AND S. V. DJoRdJEvić, Continuity of spectra and compact perturbations, Bull. Korean Math. Soc. 48 (2011), 1261-1270.

[21] J. YuAn AND G. Ji, On (n,k)-quasiparanormal operators, Studia Math. 209, 3 (2012), 289-301. 